This synopsis is based on a report entitled ' $K$ waliteitsperceptie van voedingsmiddelen, Deel 1' by J. E. B. M. Steenkamp, B. Wierenga and M. T. G. Meulenberg. Interimrapport No 27, SWOKA, Koningin Emmakade 192-195, 2518 JP The Hague, Netherlands, 1985 . xii +169 pp., 3 figs, 59 tables, 195 refs., 9 appendices. Dutch.

Available as paper copy (order R053P, $f 24.25$ including postage) or microfiches (order R053M, f 17.50 including postage) at: NARD, clo Pudoc, P.O. Box 4, 6700 AA Wageningen, Netherlands (telex 45015 blhwg).

\title{
Transversal dispersion associated with convective flow parallel to an interface separating two layers with different properties
}

C. J. van Duijn (Department of Mathematics and Informatics, Delft University of Technology, Delft, Netherlands) and S. E. A. T. M. van der Zee (Department of Soil Science and Plant Nutrition, Agricultural University, Wageningen, Netherlands)

Received 18 March 1986; accepted 29 April 1986

\begin{abstract}
The transport of solute is studied for a flow domain consisting of two regions which are separated by a sharp interface. Hydraulic and chemical properties of the two regions are different. The longitudinal dispersion coefficient is assumed to be zero and the transversal dispersion coefficient is finite. The transport equations are solved taking the correct boundary conditions at the interface into account. The validity of the assumption of an infinite transversal dispersion coefficient $\left(D_{\mathrm{T}}\right)$ often encountered in the literature is shown to be questionable for the system considered.
\end{abstract}

Key words: heterogeneity, interface, solute transport, aquifer, transverse dispersion.

Introduction. The transport of solute through porous media is generally described mathematically by solving the convection dispersion equation as given by Bear (1972). In heterogeneous flow domains this equation is solved for more than one sub-domain with appropriate conditions linking the sub-domains. For solute transport in fractured media, Tang et al. (1981) couple the transport in the fracture with a diffusion process perpendicular to the fracture surface. In a cross section of the 
fracture complete mixing is assumed (i.e., an infinitely large transversal dispersion coefficient $D_{\mathrm{T}}$ in the fracture). In recent studies by, for example, Chen (1985) and Gillham et al. (1984) the assumption of an infinite $D_{\mathrm{T}}$ is employed in the description of solute transfer in aquifers bounded by less permeable layers.

The scope of this study is to show that the assumption of an infinite $D_{\mathrm{T}}$ is not generally valid for flow domains where the longitudinal and transversal dimensions of the permeable layer are of comparable scale.

Theory. Two regions, separated by a sharp interface along the mean direction of water flow, are considered (Fig. 1), with different porous materials with respect to porosity $(n)$, interstitial water velocity $(v)$ and retardation factor $(R)$. The convection-dispersion equation (Bear, 1972) is solved for each region, taking into account continuity of solute flux and concentration at the interface. While longitudinal transport is assumed to be purely convective the value of $D_{\mathrm{T}}$ is assumed to be finite and different for the two regions $(D \sim v)$. Denoting by $V$ the loss of solute from region 1 (with the highest solute transport velocity $v_{1} / R_{1}$ ) due to the transversal dispersion process across the interface, the breakthrough at distance $x$ averaged over height $\Delta z=H$ in region 1 is given by

$$
\begin{aligned}
\bar{c}_{\mathrm{H}}(x, t) & =\frac{1}{H} \int_{0}^{H} c(x, z, t) \mathrm{d} z \\
& =1-\frac{1}{H} \int_{0}^{H}\{1-c(x, z, t)\} \mathrm{d} z=1-\frac{1}{H} V(x, t)
\end{aligned}
$$

Here $V(x, t)$ may be evaluated numerically or by analytical solution. An alternative solution, where $D_{\mathrm{T}}$ is set at an infinitely large value in region 1, thus assuring complete mixing in a cross section in this region, is given by Carslaw \& Jaeger (1958, p. 396).

Results. Breakthrough curves for three values of $R_{2}$ are shown in Fig. 2. The solid lines are obtained from an approximate analytical solution, where $D_{\mathrm{L}}=0$ and $D_{\mathrm{T}}$ is finite. The absence of longitudinal dispersion is seen clearly from the absence of spreading at first breakthrough. The dashed curves $\left(D_{\mathrm{T} 1}=\infty\right.$ in region 1) appear to agree well with the solid line for $R_{2}=1$. However, as $R_{2}$ increases the concentra-

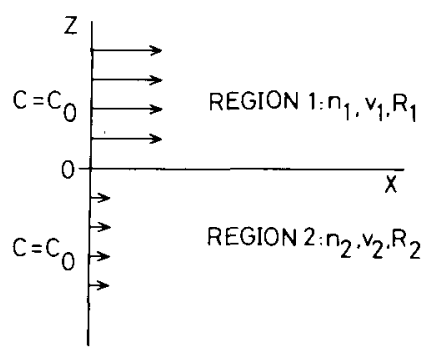

Fig. 1. Schematization of the flow domain. 


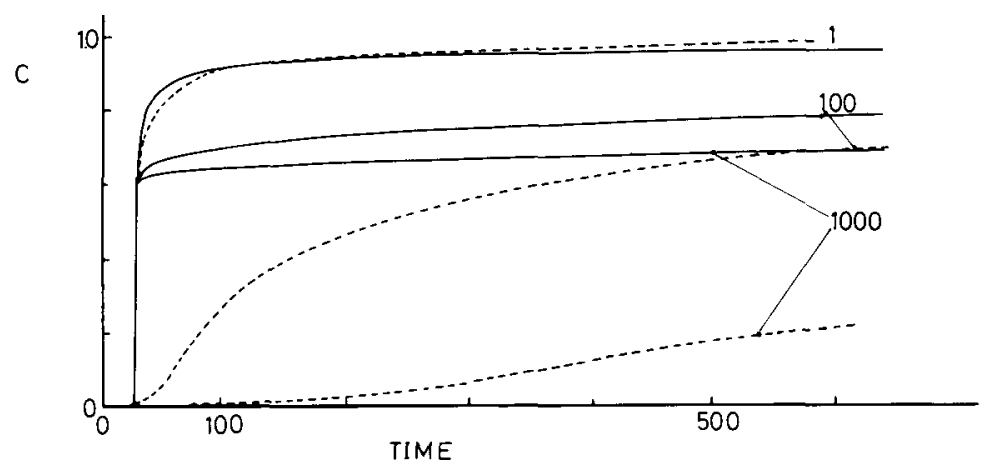

Fig. 2. Breakthrough curves at $x=1 \mathrm{~m}$. Solid lines: $H=0.2 \mathrm{~m} ; n_{1}=n_{2}=0.5 ; v_{1}=12.5 \mathrm{~m} /$ year; $v_{2}=0$; $R_{1}=1 ; D_{\mathrm{T} 2}=0.0032$ and $D_{\mathrm{T} 1}=2 D_{\mathrm{T} 2} \mathrm{~m}^{2} /$ year. Values of $R_{2}$ as indicated. Dashed lines: as solid lines with $D_{\mathrm{Tl}}=\infty$.

tion along the interface will decrease and the transverse gradient in a cross-section of region 1 will increase. As this is not accounted for in the solution of Carslaw \& Jaeger the differences between solid and dashed lines become large.

Hence the validity of an infinite value of $D_{\mathrm{T} 1}$ in region 1 is questionable in situations as considered here. The same may be true if aquifers of several meters thick are considered, whereas for realistic values of the coefficient of molecular diffusion and of fracture thickness (or root channel radius) the assumption of complete mixing in the fracture may be appropriate.

\section{References}

Bear, J., 1972. Dynamics of fluids in porous media. American Elsevier, New York.

Carslaw, H. S. \& J. C. Jaeger, 1959. Conduction of heat in solids. Clarendon Press, Oxford.

Chen, C. S., 1985. Analytical and approximate solutions to radial dispersion from an injection well to a geological unit with simultaneous diffusion into adjacent strata. Water Resources Research 21(8): 1069-1078.

Gillham, R. W., E. A. Sudicky, J. A. Cherry \& E. O. Frind, 1984. An advection diffusion concept for solute transport in heterogeneous unconsolidated geological deposits. Water Resources Research 20(3): 369-378.

Tang, D. H., E. O. Frind \& E. A. Sudicky, 1981. Contaminant transport in fractured porous media: analytical solution for a single fracture. Water Resources Research 17(3): 555-564..

This synopsis is based on a report entitled 'The transversal dispersion of solute across an interface separating two layers with different properties' by C.J. van Duijn and $S$. E. A. T. M. van der Zee. Department of Soil Science and Plant Nutrition, Agricultural University, Wageningen, 1986. $31+$ viii pp., 10 figs., 1 table, 29 refs. English.

Available as paper copy (order R054P, $f 20$ including postage) or microfiche (order R054M, f 12.50 including postage) at: NARD, clo Pudoc, P.O. Box 4, 6700 AA Wageningen, Netherlands (telex 45015 blhwg nl). 